\title{
Gender and Age Related Disparity in Oral Health Knowledge, Attitude and Practice Among Elderly Pensioners in Port Harcourt, Rivers State
}

\author{
Braimoh Omoigberai Bashiru ${ }^{1,}$ *, Achalu Ernest ${ }^{2}$, Okpako Johnson Egodotaire ${ }^{2}$ \\ ${ }^{1}$ Department of Preventive Dentistry, Faculty of Dentistry, College of Health Sciences, University of Port Harcourt, Choba Port Harcourt, \\ Nigeria \\ ${ }^{2}$ Department of Human Kinetics and Health Education, Faculty of Education, University of Port Harcourt, Choba Port Harcourt, Nigeria
}

Email address:

omoigberai.braimoh@uniport.edu.ng (B. O. Bashiru), ernest.achalu@uniport.edu.ng (A. Ernest), okpakojef@gmail.com (O. J. Egodotaire) ${ }^{*}$ Corresponding author

\section{To cite this article:}

Braimoh Omoigberai Bashiru, Achalu Ernest, Okpako Johnson Egodotaire. Gender and Age Related Disparity in Oral Health Knowledge, Attitude and Practice Among Elderly Pensioners in Port Harcourt, Rivers State. Central African Journal of Public Health.

Vol. 3, No. 3, 2017, pp. 34-39. doi: 10.11648/j.cajph.20170303.12

Received: June 16, 2017; Accepted: July 5, 2017; Published: August 9, 2017

\begin{abstract}
There is an increased interest in looking at age and gender differences in health and disease, including oral health. The objective of this study was to determine the influence of age and gender on oral health knowledge, attitude and practice of pensioners in Port Harcourt, Rivers State, Nigeria. The research was analytic descriptive survey in design. A total of 543 old people were selected by systematic random sampling. Data was collected with a self-developed Oral Health Assessment Questionnaire (OHAQ) designed in four sections (A-D) and analyzed using SPSS version 20 (IBM SPSS Armonk, New York). Relationship between variables was established using independent t-test and ANOVA, and significance determined at 0.05 alpha level. A total of 543 pensioners were involved in the study, this consisted of $295(54.3 \%)$ were males and $248(45.7 \%)$ females. The age groups 60-64 years, 65-69 years and $\geq 70$ years constituted $234(43.1 \%), 206(37.9 \%)$ and $103(19.0 \%)$ of the respondents respectively. Thirty-seven percent, $34 \%$ and $41 \%$ of the respondents had good oral knowledge, positive attitude and good behavior respectively. The oral health knowledge, attitude, and behavior scores for females were 14.8, 30.2 and 10.8 respectively. These were significantly higher in females than in males. Oral health knowledge and behavior decreased significantly with increase in age, while there was a non-significant decrease of oral health attitude with increasing age. This study found that oral health knowledge, attitude and practice of the pensioners differ significantly with gender, as well as a significant decrease in oral health knowledge and practice with increasing age. The study recommends that promotion of oral health among the pensioners.
\end{abstract}

Keywords: Age, Gender, Oral Health, Oral Health Practice

\section{Introduction}

Dental caries have decreased over time due to improvements in individual's oral health practice [1]. Healthy oral health practices are imperative among all individuals in order to decrease their risk of the development of dental diseases [2] and individuals who have good attitude and practice by brushing the teeth daily have better oral hygiene, less dental caries and periodontal disease experience than those who brush less frequently [3]. This was also found to be true for those who brush their teeth twice daily compared to those who brush once daily [1, 4-7]. Individuals with good knowledge of oral health practices are also reported to have lower prevalence of periodontal disease and dental caries $[8,9]$.

Researchers have documented association between gender and age in relation to oral health, knowledge, attitude and practice [10-13]. Poor oral health knowledge and practice are reported to be significantly higher among the older participants [13, 14]. Ogundele and Ogunsile reported that gender and age influenced oral health knowledge, attitude and practice among secondary school students [15]. However, another study revealed that age was not a 
significant factor affecting knowledge, attitude and practice [10]. Al-Omari and Harnasha [11] investigated the oral health attitudes and practice of dental students in Jordan and observed that females had better oral health attitude and practice than males.

Twice a day brushing with fluoride toothpaste is recommended for all individuals in order to help prevent against dental caries and periodontal disease. Females and males in many countries have been studied to determine which gender is more likely to brush their teeth. Reports from many studies have shown that females are more likely to brush their teeth more often than males $[16,17]$.

Interestingly, these researches reporting the influence of age and gender on oral health knowledge, attitude and practice were conducted mainly among school children. The population for this study were pensioners in Port Harcourt, Rivers State. This population group was selected for the study because they were 60 years and above. This coincides with the age at which the workers proceed on retirement from civil service. According to the United Nation Population Division [18], the Nigerian National Population Commission define the elderly in Nigeria as person's age 60 years and over, therefore, the pensioners were considered as elderly in the present study and the two terms were used interchangeably. To best of the researchers knowledge, there is little information and paucity of data on the influence of gender and age on oral health knowledge, attitude and practice among elderly people in Port Harcourt, South-South Nigeria. This study therefore, aims to contribute to the scarce literature on the oral health of the elderly; hence the objective of this study was to determine the influence of age and gender on the oral health knowledge, attitude and practice of pensioners in Port Harcourt, Rivers State.

\section{Methodology}

\subsection{Research Design}

The research design employed in this study was analytic descriptive design. Analytic descriptive design is a study design in which the variables being studied for any sample are compared for the various identified strata of the sample through the use of hypotheses [19]. Thus in this study the authors compared the oral health knowledge, attitude and practice of the pensioners in relation to their gender and age.

\subsection{Sample and Sampling Technique}

The population of the study were pensioners in Port Harcourt, Rivers State. The group was considered as elderly since it comprised of old people 60 years and above. The sample size (n) was determined according to the formula for sample size determination by Lwanga and Lemeshow [20] given as $n=\frac{z^{2} p q}{d^{2}}$ for population less than 10,000 at $95 \%$ confidence interval, standard normal deviate (z) of 1.96 and degree of accuracy (d) 0.05 . The proportion (p) of elderly with dental caries was $0.305(30.5 \%)$ [21], and the proportion (q) without dental caries was 0.695 (69.5\%). Therefore, the minimum sample size obtained for this study was 325 .

The subjects were selected by systematic random sampling. The selection was done at the Secretariat of the Nigerian Union of Pensioners (NUP) located at the State Civil Service Secretariat in Port Harcourt. Pensioners in Rivers State routinely visit the Secretariat daily and congregate once monthly for their meetings. The register of the pensioners constituted the sampling frame for this study (source: NUP Secretariat) and every second subject was selected from the register. Subjects selected who were not present in a particular visit were contacted through their phone numbers for subsequent visit.

\subsection{Instrument for Data Collection}

Data for this study was from primary source. Data was collected by the use of questionnaire. The questionnaire was a structured self-developed Oral Health Assessment Questionnaire (OHAQ) designed in four sections (A-D). Section A contained information on socio-demographic data; section B, C and D on oral health knowledge, practice and attitudes respectively. Section A contained the demographic information (gender and age), section $\mathrm{B}$ and $\mathrm{C}$ contained questions on oral health knowledge and practice both were assessed on a scale of yes (1 point) or no $(0$ point $)$ for positively constructed questions and yes ( 0 point) or no (1) for negative questions.

The oral health knowledge of the pensioners was assessed using 20 questions. These included questions on the accumulation of plaque on the teeth, meaning of plaque and its effect on dentition and the gum, the cause of tooth decay, purpose of tooth brushing, meaning of gum bleeding and its reasons, methods to prevent gum bleeding, effect of sugar particularly soft/fizzy drinks on teeth, methods of prevention of tooth decay, methods of prevention of gum disease, effect of fluorides on teeth, effect caries on aesthetics, relationship of gum disease to diabetes, heart disease, low birth weight. The oral health behavior of the participants was assessed using 16 questions. These included questions on frequency and time of tooth brushing, duration of tooth brushing, material used for brushing teeth, reasons for change of tooth brush, materials used for cleaning the teeth other than tooth brush, reasons for visiting a dentist, frequency of consumption of sweets, and bad habits like cigarette smoking.

The oral health attitude of the pensioners was contained in section $\mathrm{D}$ and it had 13 questions. These included questions on attitudes towards regular dental visits, cigarette smoking habit, cleaning of teeth without using paste, care of the teeth, bothering about color of teeth, services / care provided by a dentist, as well as attitude towards dental care and body care in general and involvement in the dental treatment. The questions were assessed on a 4 point modified Likert scale of strongly agree ( 4 points) agree ( 3 points), disagree ( 2 points) and strongly disagree (1 point) for positive questions and strongly agree (1 point), agree ( 2 points), disagree ( 3 points) and strongly disagree (4 points) for negative questions. 


\subsection{Validity and Reliability of the Instrument}

Validity is defined as the accuracy, quality and appropriateness of the modalities adopted for finding answers to the research questions [22]. The researcher believes that this research study is accurate and valid due to the fact that procedures adopted for this study are from scientific and peer reviewed sources. The validity was further justified by presenting the data collecting instrument to the second and third author and based on their expert opinion, comments, criticisms and observations the instrument was modified.

The reliability of the instrument was done using pensioners different from those recruited for the study. Twenty of them were selected; the selected pensioners completed the questionnaire and were examined by the researcher. The filling of the questionnaire and examination was repeated after an interval of one week. The reliability of the instrument was determined using the Cronbach alpha and alpha coefficient of 0.82 was obtained. The reliability testing also served as the pilot-test for the data collecting instrument, from the reaction of the participants to the questionnaire, it was evident that they quite understood the question items. There was evidence that some words were not understood under attitude and knowledge section. This were identified and modified according to the level of participants understanding.

\subsection{Procedure for Data Collection}

Five trained research Assistants were used to ensure proper distribution of the questionnaire to the participants. Rapport was established with the pensioners, the researcher and trained research Assistants explained the purpose of the research to the pensioners and highlighted the importance of privacy, confidentiality and consent. Several visits were made to the Secretariat and at each visit questionnaires were distributed to pensioners for completion. Five hundred and forty three (543) copies of the questionnaire were administered to the respondents and all were retrieved. This took a period of two years from April 2015- March 2017. The study was approved by the Research Ethics Committee, University of Port Harcourt. Pensioners who retired from public service of Rivers State government voluntarily or retired as a result of years of service, who were below the age of 60 years were excluded from the study, since they do not meet the age to be classified as elderly.

\subsection{Procedure for Data Analysis}

The completed copies of the questionnaires were collated, coded and entered into the Statistical Package for Social Sciences (SPSS) spread sheet. The data was subsequently analyzed using SPSS version 20 (IBM SPSS Armonk, New York). Descriptive statistics of percentage, mean and standard deviation were used describe the oral health knowledge, attitude and practice of the subjects. Individual knowledge score varied from 0-20. The practice score of individual varied from 0-16. Similarly, attitude score for individual varied from 13-52. The knowledge, attitude and behaviour mean score for the population was calculated and respondents score equal to or greater than the population mean score were rated as having good knowledge, good behavior and positive attitude, and those with score less than the mean were rated as having poor knowledge, poor behavior and negative attitude. The mean knowledge, attitude and behavior score was also calculated for gender and age.

Inferential statistics of independent $t$-test and analysis of variance (ANOVA) was used to test the association between oral health knowledge, attitude and practice with gender and age. The hypotheses were rejected if the t-calculated and Fcalculated values were equal to or greater than their respective $\mathrm{t}$-critical and $\mathrm{F}$-critical values. In addition, the magnitude of association between the independent variable (age) and the dependent variables (knowledge, attitude and practice) was determine by the correlation ratio (cE). According to Nwankwo, in order to identify the magnitude of a significant relationship or association between variables which level of significance was determine by ANOVA, correlation ratio is applied to the $\mathrm{F}$ calculated value [23]. Interpretation of the nature of relationship was done according to Nwana [24]. According to Nwana, 00-0.19 implies "no relationship or very low (weak) relationship", 0.20-0.39 "low (weak) relationship", 0.40-0.69 "moderate relationship", 0.70-0.89 "high (strong) relationship" and 0.90-1.00 "very high (strong) relationship".

\section{Results}

There were more male pensioners than female pensioners, $295(54.3 \%)$ were males and $248(45.7 \%)$ were females. There were also more respondents in the 60-64 years age group $234(43.1 \%)$, the age group 65-69 years constituted $206(37.9 \%)$ of the respondents and $103(19.0 \%)$ of the respondents were $\geq 70$ years.

The mean knowledge score of the participants was 12.23 $(\mathrm{SD}=1.57)$. Majority of the participants $342(63.0 \%)$ had poor oral health knowledge and $201(37.0 \%)$ had good knowledge of oral health (Figure 1). Sixty-eight point seven percent knew that plaque is a soft deposit that forms on the surface of the teeth, $63 \%$ knew that brushing teeth prevent tooth decay, $56.3 \%$ knew that brushing the teeth prevent gum disease and $63 \%$ knew that consumption of sugar causes dental caries. Only $48.1 \%$ knew that using fluoride containing toothpaste prevent tooth decay, $39.7 \%$ knew that smoking makes gum disease worse and $40.2 \%$ knew that plaque is mainly bacteria.

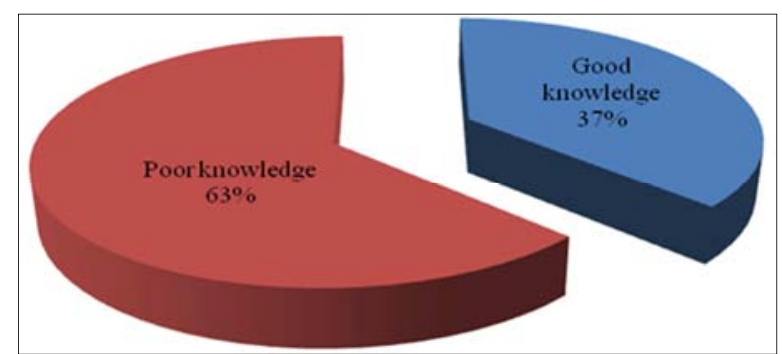

Figure 1. Knowledge of Oral Health among the Pensioners in Port Harcourt, Rivers State. 
The mean behavior score of the participants was 8.76 $(\mathrm{SD}=1.10)$. More than half of the participants $319(58.7 \%)$ had poor oral health behavior and $224(41.3 \%)$ had good oral health behavior (Figure 2). Sixty-two percent of the respondents cleaned their teeth with tooth brush and paste alone and $38 \%$ used toothbrush and paste in combination with chewing stick. None of the respondents used dental floss for inter-dental cleaning. Approximately, 65\% of the participants cleaned their teeth once daily. Females significantly brushed their teeth with tooth brush and paste and twice daily than males.

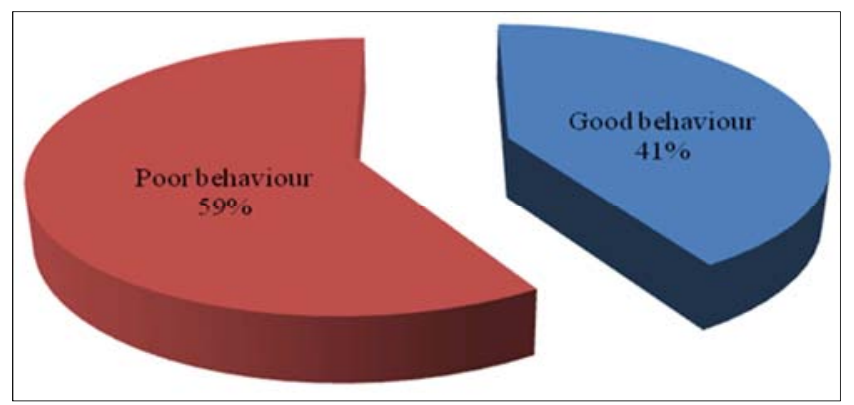

Figure 2. Oral Health Behavior among the Pensioners in Port Harcourt, Rivers State.

The mean attitude score of the respondents was 27.61 $(\mathrm{SD}=1.31)$. Majority of the respondents $361(66.5 \%)$ had negative oral health attitude and $182(33.5 \%)$ had positive oral health attitude (Figure 3). Majority of sample (67\%) indicated that regular dental visit was necessary and $73 \%$ indicated that dental visit was only necessary when in pains.

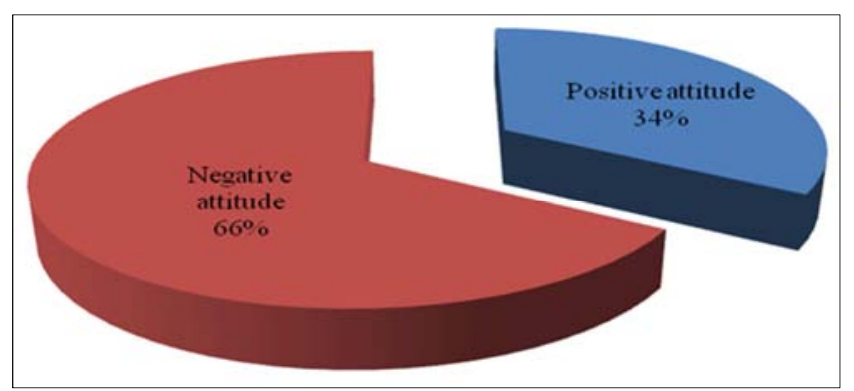

Figure 3. Oral Health Attitude among the Pensioners in Port Harcourt, Rivers State.

Table 1 shows the mean score and standard deviation for knowledge, attitude and practice according to gender of the participants. The knowledge score was $14.8 \pm 0.8$ and $9.7 \pm 0.7$, the attitude score $30.2 \pm 1.3$ and $25.1 \pm 1.6$ and practice score $10.8 \pm 0.8$ and $6.7 \pm 1.4$ for female and male respectively. The knowledge, attitude and practice scores were all higher in females than in males, indicating that there is difference in oral health knowledge, attitude and practice with gender. The results also showed that oral health knowledge, attitude and practice of the pensioners differ significantly with gender.
Table 1. t- test of the Influence of Gender on Oral Health Knowledge, Attitude and Practice of the Pensioners.

\begin{tabular}{llllllll}
\hline \multirow{2}{*}{ Gender } & \multirow{2}{*}{ N } & \multicolumn{2}{l}{ Knowledge } & \multicolumn{2}{l}{ Attitude } & \multicolumn{3}{l}{ Practice } \\
\cline { 3 - 8 } & & Mean & SD & Mean & SD & Mean & SD \\
\hline Female & 248 & 14.8 & 0.8 & 30.2 & 1.3 & 10.8 & 0.8 \\
Male & 295 & 9.7 & 0.7 & 25.1 & 1.6 & 6.7 & 1.4 \\
df & & 541 & & 541 & & 541 & \\
t-cal & & 4.87 & & 4.58 & & 5.12 & \\
t-cri & & 1.965 & & 1.965 & & 1.965 & \\
Decision & & Significant & Significant & Significant \\
\hline
\end{tabular}

Table 2 shows the answer to research question 2 and hypothesis 2. The table shows that the oral knowledge, attitude and practice of the pensioners differ with age. Whereas the knowledge score was $15.4 \pm 0.5,11.7 \pm 0.7$ and $9.6 \pm 1.1$ for age groups $60-64$ years, 65-69 years and $\geq 70$ years respectively, the attitude score was $32.1 \pm 1.6,28.7 \pm 1.3$ and $22.3 \pm 0.8$ for age groups 60-64 years, 65-69 years and $\geq 70$ years respectively. The practice score for $60-64$ years was $11.6 \pm 1.3,65-69$ years, $8.9 \pm 1.1$ and $\geq 70$ years $5.8 \pm 0.9$. These results showed inverse relationship between oral knowledge, attitude, practice and age of the pensioners, indicating that knowledge, attitude, practice decreases with increasing age and conversely too. Whereas the decrease of oral health attitude with increasing age was non-significant, there was a significant decrease of oral knowledge and practice with increasing age. The correlation ratio of the association between age and practice was -0.33 and between age and knowledge was -0.27 . This indicated a weak and negative association between age and oral health practice as well as between age and oral health knowledge. The negative association further confirms the inverse relationship of age with knowledge and practice.

Table 2. ANOVA Test of the Influence of age on Oral Health Knowledge, Attitude and Practice of the Pensioners.

\begin{tabular}{|c|c|c|c|c|c|c|c|}
\hline \multirow{2}{*}{ Age in years } & \multirow{2}{*}{$\mathbf{N}$} & \multicolumn{2}{|c|}{ Knowledge } & \multicolumn{2}{|c|}{ Attitude } & \multicolumn{2}{|c|}{ Practice } \\
\hline & & Mean & SD & Mean & SD & Mean & SD \\
\hline $60-64$ years & 234 & 15.4 & 0.5 & 32.1 & 1.6 & 11.6 & 1.3 \\
\hline $65-69$ years & 206 & 11.7 & 0.7 & 28.7 & 1.3 & 8.9 & 1.1 \\
\hline$\geq 70$ years & 103 & 9.6 & 1.1 & 22.3 & 0.8 & 5.8 & 0.9 \\
\hline \multicolumn{2}{|l|}{ df } & \multicolumn{2}{|c|}{$\mathrm{df} 1=2, \mathrm{df} 2=540$} & \multicolumn{2}{|c|}{$\mathrm{df} 1=2, \mathrm{df} 2=540$} & \multicolumn{2}{|c|}{$\mathrm{df} 1=2, \mathrm{df} 2=540$} \\
\hline \multicolumn{2}{|l|}{ F-cal } & \multicolumn{2}{|c|}{4.31} & \multicolumn{2}{|c|}{2.85} & \multicolumn{2}{|c|}{6.21} \\
\hline \multicolumn{2}{|l|}{ F-cri } & \multicolumn{2}{|l|}{3.00} & \multicolumn{2}{|l|}{3.00} & \multicolumn{2}{|l|}{3.00} \\
\hline \multirow{2}{*}{\multicolumn{2}{|c|}{$\begin{array}{l}\text { Decision } \\
\text { correlation ratio } \\
(\mathrm{cE})\end{array}$}} & \multicolumn{2}{|c|}{ Significant } & \multicolumn{2}{|c|}{ Not significant } & \multicolumn{2}{|c|}{ Significant } \\
\hline & & -0.27 & & & & -0.33 & \\
\hline
\end{tabular}

\section{Discussion}

The present study showed that majority of the respondents had poor oral health knowledge and behavior, and negative attitude towards oral health. The knowledge, attitude and practice scores were higher in female compared to male. This indicates that gender influenced oral health knowledge, attitude and practice of the pensioners and the influence was significant. These results are in conformity with the results of other studies. Singh et al. [13] reported a significant 
influence of gender on oral health knowledge, attitude and practice; females had significant better knowledge, attitude and practice than the males. Al-Ansari and Honkala [17], evaluated population's knowledge of oral health and observed that female knowledge was statistically higher than that of male. Al-Omari and Harnasha [11] investigated the oral health attitudes and practice dental students in Jordan and observed that oral health attitude and practice were significantly higher in females than males. Ogundele and Ogunsile [15] and Braimoh and Owoturo [10] in their studies observed that though females had better knowledge, attitude and practice than males, the influence of gender on attitude and practice was significant and non-significant in relation to knowledge. Al-Sharbatti and Sadek [14] observed a nonsignificant relationship between knowledge, attitude and practice and gender. The better knowledge, attitude and practice exhibited by females may be due the fact that females are usually more concerned about their body and appearance, as a result are more likely to visit the dentist and become more educated about their oral health [13].

In the present study, $62 \%$ of the pensioners cleaned their teeth with tooth brush and paste. This was less than $81 \%$ reported by Olushile et al [25]. The variation may be due to difference in the study population and lack of money to procure these oral hygiene materials, since the participants are pensioners who are not paid their pension allowance regularly. Hence there is need to subsidized the cost of tooth paste and brush to make it affordable to this group. In addition, none of the participants in the present study used dental floss for cleaning; this is in agreement with previous report among Nigerians [10]. However, the use of dental floss has been reported in other studies [11, 12, 26]. Furthermore, $65 \%$ of the study population brushed their teeth once a day. This result is comparable to the results other studies $[27,28]$. While twice a day tooth brushing seems to be an established practice in several industrialized countries [29], this practice is far from being realized in several other countries [30].

Regular visit to the dentist is not a common event in developing countries. In this study, $67 \%$ of the pensioners indicated that regular visit to the dentist was not necessary and $73 \%$ indicated that dental visit was only necessary when in pain. This result is in agreement with other studies which reported that dental visits were motivated by pain and the need for emergency care [31].

Regarding age, age of the respondents was significantly inversely related to knowledge and practice and nonsignificantly inversely related to attitude. The significant inverse relationship was further confirmed by the negative correlation ratio $(-0.27$ for knowledge and -0.33 for practice) obtained in the present study, suggesting that as the age of the participants' increases there was a significant decrease in the knowledge and practices of the pensioners. Al-Sharbatti and Sadek [14] documented similar findings. The research showed that poor knowledge score was significantly higher among the older participants. They also reported that poor oral health practice was significantly higher among older participants. The study further showed a non-significant inverse relationship between age and attitude similar to what was observed in the present study. Ogundele and Ogunsile [15] and Singh et al. [13] reported that as the age increases, oral health knowledge, attitude and practice becomes significantly poor. The reason for this is not known, however this may not be unconnected to the fact that old people show less concern about their health and due to financial hardship may not be able to obtain dental care and procure materials required for oral self-care.

\section{Conclusion}

Majority of the respondents had poor oral health knowledge and behavior, and negative attitude towards oral health. The oral health knowledge, attitude and practice of the pensioners differ significantly with gender. There was a significant decrease in oral health knowledge and practice with increasing age. There was a decrease in oral health attitude with increasing age, this was however nonsignificant. The study recommends that promotion of oral health and the prevention of oral diseases among the pensioners should be given high priority with extra attention to males and the aged.

\section{References}

[1] Pilot T, Miyazaki H. Global results: 15 years of CPITN epidemiology. Int J Dent 1994; 44(1): 553-60.

[2] Sheiham A, Watt R. The common risk factor approach-a rational basis for promoting oral health. Community Dent Oral Epidemiol 2000; 28: 399-406.

[3] Al-Ansari J, Honkala E, Honkala S. Oral health knowledge and behavior among male health sciences college students in Kuwait. BMC Oral Health 2003; 3: 2.

[4] Wardle J, Steptoe A. The European health and practice survey: Rationale, methods and initial results from the United Kingdom. Soc Sci Med 1991; 33: 925-36.

[5] Braimoh OB, Udeabor SE. Self-assessed oral health behavior and knowledge of undergraduate medical students. Afri J Med Sci 2012; 5(1): 55-9.

[6] Braimoh OB, Ilochonwu NA, Egbor PE. Oral health practices and status of public transport operators in Choba Port Harcourt, Rivers State. J Sci 2015; 5(7): 555-9.

[7] Arigbede OA, Umanah AU, Ukegheson GE, Braimoh OB, Omitola OG, Akadiri AO. Prevalence of dental caries and oral hygiene status of a screened population in Port Harcourt, State, Nigeria. J Int Soc Prev Community Dent 2015; 5(1): 5963.

[8] Chen M, Andersen R, Barmes D. Comparing oral health care systems: A second international collaborative study. World Health Organization, Geneva. 1997.

[9] Broadbent, J. M., Thomson, W. M., \& Poulton, R. Oral health beliefs in adolescence and oral health in young adulthood. J Dent Res 2006; 85(4): 339-43. 
[10] Braimoh OB, Owoturo EO. Oral health knowledge, attitude and behavior of medical, pharmacy and nursing students at the University of Port Harcourt, Nigeria. J Oral Res Rev 2016; 8(2): 66-71.

[11] Al-Omari QD, Harnasha AA. Gender-specific oral health attitudes and behavior among dental students in Jordan. J Contem Dent Pract 2005; 6: 107-14.

[12] Kawas SA, Fakhruddin KS, Rehman BU. A comparative study of oral health attitudes and behavior between dental and medical students; the impact of dental education in United Arab Emirates. J Int Dent Med Res 2009; 2: 6-10.

[13] Singh K, Kochhar S, Mittal V, Agrawal A, Chaudhary H, Anandani C. Oral health: knowledge, attitude and behavior among Indian population. Educ Res 2012; 3(1): 66-71.

[14] Al-Sharbatti S, Sadek M. Oral Health Knowledge, Attitudes and Practices of the elderly in Ajman, UAE. Gulf Med J 2014; 3(S2): S152-S64.

[15] Ogundele BO, Ogunsile SE. Dental health knowledge, attitude and practice on the occurrence of dental caries among adolescents in a local government area of Oyo State. Asian J Epidemiol 2008; 1(2): 64-71.

[16] Kassak KM, Dagher R, Doughan B. Oral hygiene and lifestyle correlates among new undergraduate university students in Lebanon. J Am Coll Health 2001; 50(1): 15-20.

[17] Al-Ansari JM, Honkala S. Gender differences in oral health knowledge and behavoir of the health sciences college students in Kuwait. J Allied Health 2007; 36(1): 41-6.

[18] United Nation Population Division. World population prospect: The 2002 revision. New York, United Nations. (2003).

[19] Ogomaka PMC. Types of research. In A. J. Isangedighi and P. M. C. Ogomaka (Eds). Educational research method. Owerri, Totan Publishers Limited. 1992.

[20] Lwanga SK, Lemeshow S. Sample size determination in
Health studies: A Practical Manual. World Health Organisation, Geneva. 1991.

[21] Esan TA, Oziegbe EO. Oral health status and treatment needs of elderly people in Ile-ife, Nigeria. East Afri J Pub Health 2013; 10(3): 535-8.

[22] Kumar R. A step by step for beginners. Research methodology ( $3^{\text {rd }}$ ed.) New Delhi, SAGE. 2011.

[23] Nwankwo OC. Practical guide to research writing $5^{\text {th }}$ ed. Choba, Port Harcourt, University of Port Harcourt Press Limited. 2013.

[24] Nwana BG. Introduction to educational research. Ibadan, Heinemann Educational Book Nigeria Limited. (1992).

[25] Olusile AO, Adeniyi AA, Orebanjo O. Self-rated oral health status, oral health service utilization, and oral hygiene practices among adult Nigerians. BMC Oral Health 2014; 14: 140.

[26] Khami MR, Virtanem JI, Jafarian M, Murtomaa H. Prevention-oriented practice of Iranian senior dental students. Eur. J. Dent. Educ. 2007; 11: 48-53.

[27] Jeboda SO, Adeniyi AA, Ogunbodede EO: Assessment of preventive oral health knowledge and practices among rural and urban mothers in Lagos state. Niger. Postgrad. Med. J. 2009; 16: 239-44.

[28] Umesi-Koleoso DC, Ayanbadejo PO: Oral hygiene practices among adolescents in Surulere, Lagos State, Nigeria. Nig. Q. J. Hosp. Med. 2007; 17: 112-5.

[29] Davies RM, Davies GM, Ellwood RP. Prevention. Part 4: Toothbrushing: What advice should be given to patients? $\mathrm{Br}$ Dent J 2003; 195: 135-41.

[30] Behbehani JM, Shah NM. Oral health in Kuwait before the Gulf War. Prin Med Pract 2002; 11: 36-43.

[31] Azodo CC, Ogordi PU. Pain-related pediatric dental attendance in a Nigerian dental clinic. J. Oral Res. Rev. 2016; 8: 6-11. 